\title{
Alterações de custo e prazo em obras públicas
}

\author{
Time and cost overrun in public projects
}

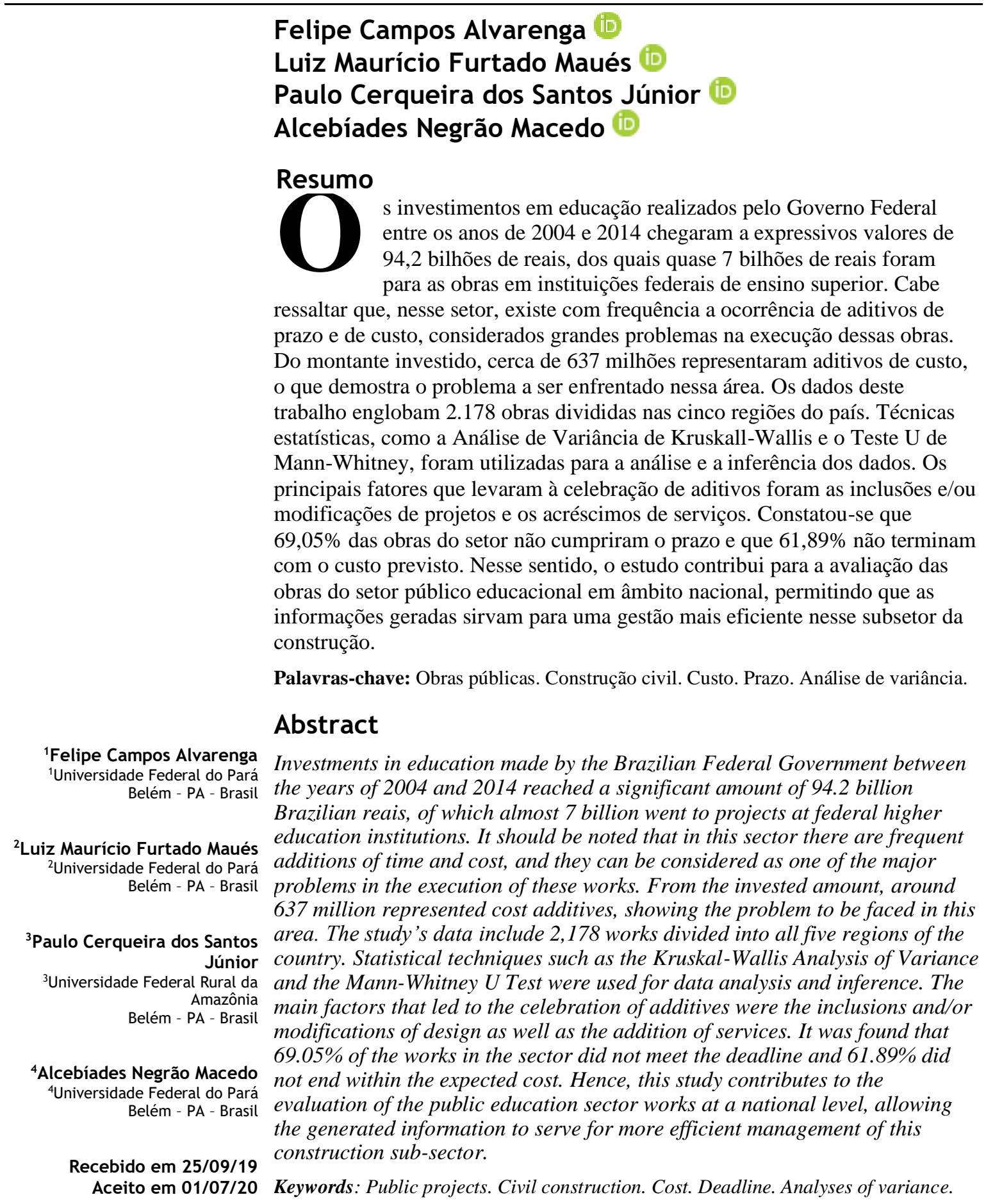




\section{Introdução}

O papel primordial de um governo é garantir melhor qualidade de vida aos seus administrados, sempre visando ao cumprimento das necessidades coletivas da sociedade em todos os seus aspectos, entre eles a infraestrutura urbana. Não à toa, a administração pública é a principal expoente nesse setor, o que fornece à área de obras públicas um massivo destaque na gestão governamental (ALTOUNIAN, 2016). Cabe ressaltar que a construção de obras públicas é regida por uma legislação própria, a qual dita os ritos desde a fase de contratação da responsável pela obra até a conclusão desta. Nesse sentido, Santos (2015) afirma que esses trabalhos devem ter uma gestão e uma fiscalização eficientes e eficazes, para que se obtenham os melhores resultados com a contratação.

Nesse ponto, vale frisar que a lei de maior importância no que tange aos contratos administrativos é a Lei $n^{\circ}$ 8.666 (BRASIL, 1993), também chamada de "Lei das Licitações". Na visão de Mattos (2014), as críticas contundentes a essa lei ocorrem devido ao engessamento do espaço de ação do gestor público, o que pode, ao invés de aliviar os custos da administração, acarretar aumento significativo de suas despesas, pois, em situações nas quais o contrato celebrado entre o licitante e a administração pública não é plausível de ser concluído dentro dos termos previamente estabelecidos na licitação, uma alternativa prevista em lei é a alteração do contrato, sendo frequente a celebração de aditivos, como referendado na pesquisa de Perez (2011). Portanto, essa alteração pode ocorrer de duas formas: unilateralmente, para melhor adequação às finalidades do interesse público, e por acordo entre as partes, nos termos do art. 65, II (BRASIL, 1993).

As alterações de contrato, muitas vezes, podem resultar em prejuízos para a administração pública, seja pelo impedimento do início das atividades previstas na nova edificação devido ao atraso na entrega (MAUÉS et al., 2017; FILIPPI; MELHADO, 2015), problema também identificado por autores de outros países, como Larsen et al. (2016), na Dinamarca, e Mahamid (2013), na Palestina, seja pelos prejuízos econômicos gerados pela má programação do custo final de um empreendimento, fatos que geram a necessidade de realizar empenhos adicionais para que os projetos sejam concluídos. Esta situação é corroborada nas pesquisas realizadas por Flyvbjerg, Holm e Buhl (2002), na Dinamarca, Senouci, Ismail e Eldin (2016), no Qatar, Shehu et al. (2014), na Malasia, e Sweis et al. (2008) e Aragão (2015), no Brasil, entre outros.

Analisar as principais causas de aditivos de custo e de prazo de obras contribui para a busca de soluções que irão impactar na redução da ocorrência desses fatores nos projetos, resultando em melhor eficiência na gestão e em benefício à sociedade (RASMUSSEM, 2013; SANTOS; STARLING; ANDERY, 2014; RIBEIRO, 2015). Ademais, se, no decorrer do ciclo de vida do empreendimento, os processos de gerenciamento forem mais eficientes e eficazes, pode-se tratar os motivos responsáveis pela mudança nas condições iniciais estabelecidas no contrato, dando-se respostas mais rápidas e precisas, que são condições essenciais para a preservação da qualidade esperada e para o bom uso dos recursos públicos (RICARDINO; SILVA; ALENCAR, 2013).

É importante ressaltar que os aditivos de custo e de prazo acarretam prejuízos, seja de ordem financeira, quando se investe mais do que a dotação orçamentária inicial, seja por meio da postergação do uso da edificação, em função dos aditivos de prazo. Ambos acarretam problemas para os contratantes, contratados e usuários finais. Um estudo sobre a prática de aditivos em âmbito nacional nas instituições federais de ensino superior (Ifes) ainda é uma lacuna no conhecimento, adiando a identificação de possíveis soluções para esse problema de fundamental importância, pois nesse cenário as instituições ficam penalizadas quanto à expansão de serviços relevantes prestados à sociedade, seja no ensino, na pesquisa ou na extensão.

Portanto, o objetivo deste trabalho é diagnosticar os aditivos contratuais celebrados em obras públicas nas Ifes e os principais motivos usados como justificativas para a celebração deles. Com isso, espera-se que esta pesquisa seja um passo inicial para avaliar as diferenças regionais em termos de quantitativos de aditivos, a qual possa, futuramente, inspirar estudos focados na mitigação dos fatores mais frequentes responsáveis pelo aumento de custo e/ou do prazo no cenário de obras públicas no setor educacional.

\section{Prazo e custo de obras}

Segundo o IBGE (INSTITUTO..., 2018), a administração pública destinou em 2016 cerca de 94 bilhões de reais para a indústria da construção civil, o que representou 31,5\% do total gasto pelo setor, demonstrando que os investimentos públicos representam aproximadamente um terço dos gastos. Esse fato pode sinalizar que o setor público é um grande contratante e, portanto, deve ser considerado nas estratégias de negócios das empresas de construção no país. 
Nesse contexto, o atraso em obras que envolvem investimento público é um dos problemas de maior relevância na indústria da construção, além de figurar no topo dos problemas mais recorrentes nesse setor (MAHAMID; BRULAND; DMAIDI, 2011). Esse fato proporciona uma expressiva quantidade de obras, que ultrapassa o limite contratual de execução previsto inicialmente, sendo esse fenômeno gerado por razões de naturezas diversas, amplamente reportado nas literaturas nacional e internacional, como nas pesquisas nacionais realizadas por Maués et al. (2019) e Cruz, Santos e Mendes (2018).

Existem diversos trabalhos publicados nos últimos 15 anos que buscam identificar as causas dos atrasos em obras e sua hierarquia. Com efeito, pode-se citar os pesquisadores que foram utilizados nesta pesquisa, por serem os que apresentaram maior aderência ao tema-alvo deste trabalho (Quadro 1).

No levantamento contido no Quadro 1 foi possível observar que os atrasos na entrega das obras, assim como o aumento do custo para realizá-las, é um tema atual e que pesquisadores de diversos países buscam se aprofundar sobre esse problema com o objetivo de encontrar alternativas para minimizar seus efeitos na construção. Ademais, observa-se a grande relevância do tema no ramo da construção civil, seja no Brasil, seja no mundo, indicando a necessidade de identificar os motivos geradores de atrasos em obras e, dessa forma, alcançar soluções que trarão mais eficiência na gestão dos contratos. Em função dessa necessidade e de acordo com a bibliografia pesquisada neste trabalho, os autores consultados identificaram fatores que resultaram em atrasos e/ou aumento de custo de obras, conforme demostrado no Quadro 2.

Quadro 1 - Pesquisas consultadas que abordam o prazo e o custo de obras

\begin{tabular}{|c|c|c|c|c|}
\hline Autor(es) & Ano de publicação & País/Região & Prazo & Custo \\
\hline Flyvbjerg, Holm e Buhl & 2004 & Noruega & & $\mathrm{x}$ \\
\hline Couto e Teixeira & 2005 & Portugal & $\mathrm{x}$ & \\
\hline Moura e Teixeira & 2007 & Portugal & & $\mathrm{x}$ \\
\hline Sweis et al. & 2008 & Jordânia & $\mathrm{x}$ & \\
\hline Abd El-Razek, Bassioni e Mobarak & 2008 & Gana & $\mathrm{x}$ & \\
\hline Ahsan e Gunawam & 2010 & Países Asiáticos & $\mathrm{x}$ & $\mathrm{x}$ \\
\hline Monteiro & 2010 & Portugal & & $\mathrm{x}$ \\
\hline Doloi et al. & 2012 & Índia & $\mathrm{x}$ & \\
\hline Mahamid & 2013 & Turquia & $\mathrm{x}$ & \\
\hline Alinaitwe, Apolot e Tindiwensi & 2013 & Uganda & $\mathrm{x}$ & \\
\hline Alnuaimi e Mohsin & 2013 & Omã & $\mathrm{x}$ & \\
\hline Love et al. & 2013 & Austrália & & $\mathrm{x}$ \\
\hline Rasmussem & 2013 & Brasil & $\mathrm{x}$ & \\
\hline Ricardino, Silva e Alencar & 2013 & Brasil & $\mathrm{x}$ & \\
\hline Silva & 2014 & Brasil & & $\mathrm{x}$ \\
\hline Cheng & 2014 & China & & $\mathrm{x}$ \\
\hline Shehu et al. & 2014 & Malásia & & $\mathrm{x}$ \\
\hline Santos, Starling e Andery & 2014 & Brasil & & $\mathrm{x}$ \\
\hline Gunduz, Nielsen e Ozdemir & 2015 & Turquia & $\mathrm{x}$ & \\
\hline Ahiaga-Dagbui et al. & 2015 & - & & $\mathrm{x}$ \\
\hline Filippi e Melhado & 2015 & Brasil & $\mathrm{x}$ & \\
\hline Love et al. & 2015 & Austrália & $\mathrm{x}$ & $\mathrm{x}$ \\
\hline Ribeiro & 2015 & Brasil & & $\mathrm{x}$ \\
\hline Santos & 2015 & Brasil & $\mathrm{x}$ & \\
\hline Aziz e Abdel-Hakam & 2016 & Egito & $\mathrm{x}$ & \\
\hline Jung, Kim e Lee & 2016 & Coreia & & $\mathrm{x}$ \\
\hline Larsen et al. & 2016 & Dinamarca & $\mathrm{x}$ & $\mathrm{x}$ \\
\hline Senouci, Ismail e Eldin & 2016 & Qatar & $\mathrm{x}$ & $\mathrm{x}$ \\
\hline Tipili e Yakubu & 2017 & Nigéria & $\mathrm{x}$ & $\mathrm{x}$ \\
\hline Adam, Josephson e Lindahl & 2017 & Noruega & $\mathrm{x}$ & $\mathrm{x}$ \\
\hline Al-Hazim, Salem e Ahmad & 2017 & Jordânia & & $\mathrm{x}$ \\
\hline Aljohani, Ahiaga-Dagbui e Moore & 2017 & - & $\mathrm{x}$ & $\mathrm{x}$ \\
\hline Freitas & 2017 & Brasil & $\mathrm{x}$ & $\mathrm{x}$ \\
\hline Maués et al. & 2017 & Brasil & $\mathrm{x}$ & \\
\hline Oyegoke e Al Kyumi & 2017 & Omã & $\mathrm{x}$ & \\
\hline
\end{tabular}


Quadro 2 - Fatores que deram origem aos atrasos e aumento de custos de obras (Continua...)

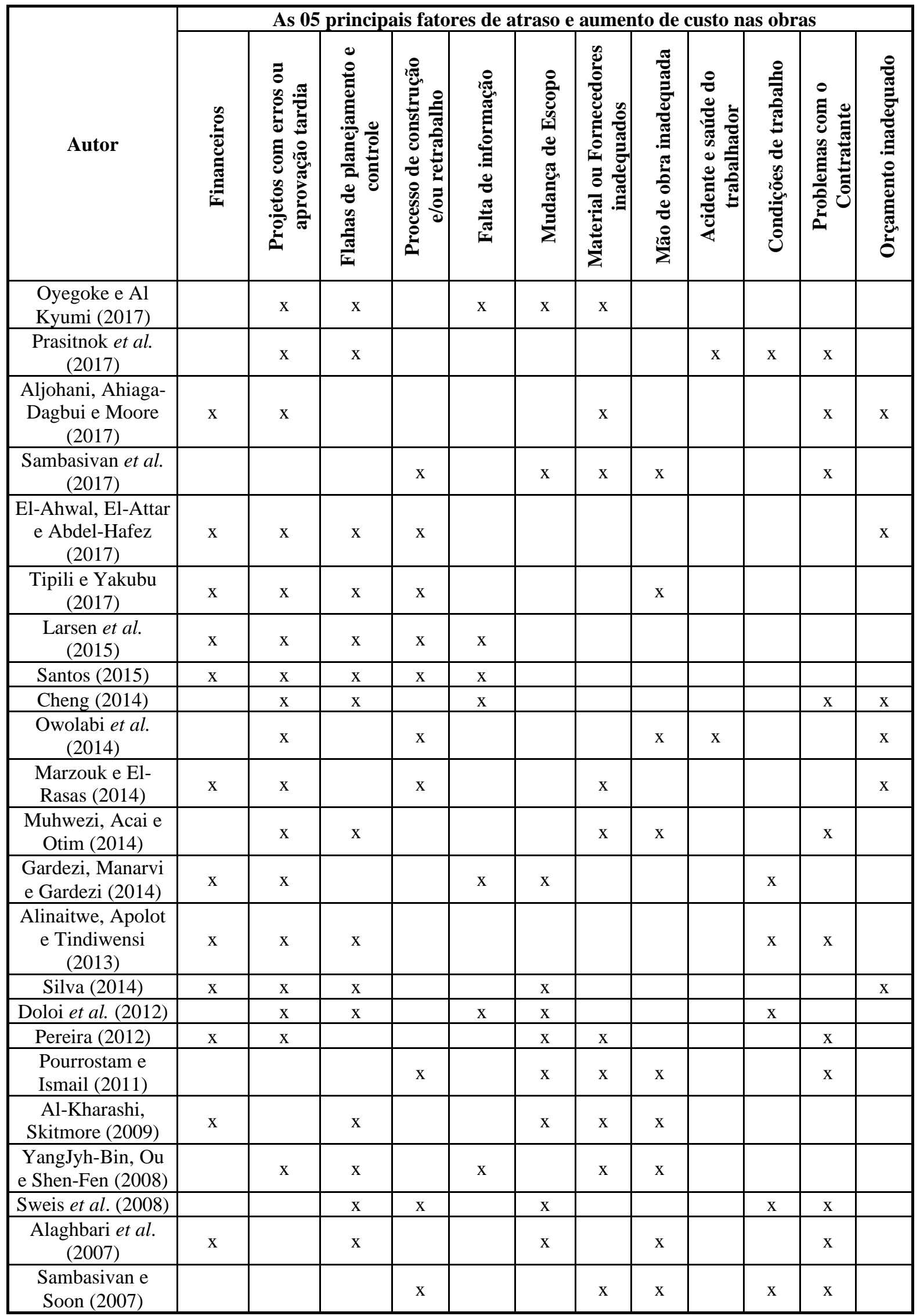


Quadro 2 - Fatores que deram origem aos atrasos e aumento de custos de obras (continuação)

\begin{tabular}{|c|c|c|c|c|c|c|c|c|c|c|c|c|}
\hline \multirow[b]{2}{*}{ Autor } & \multicolumn{12}{|c|}{ As 05 principais fatores de atraso e aumento de custo nas obras } \\
\hline & : & 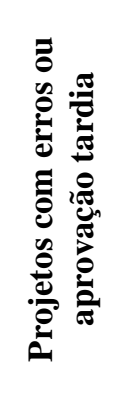 & 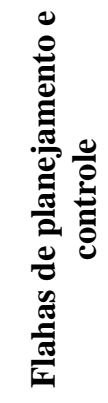 & 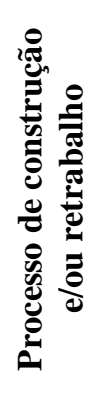 & 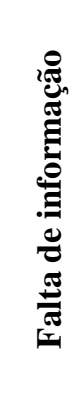 & 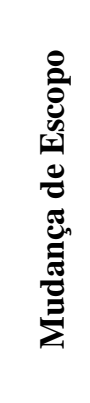 & 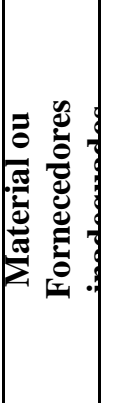 & 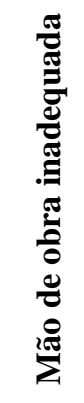 & 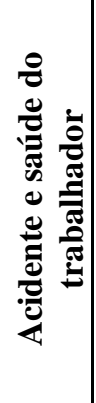 & 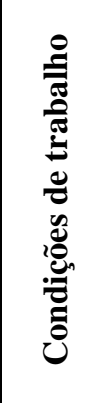 & 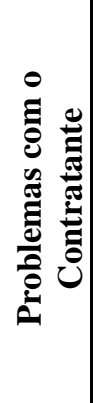 & 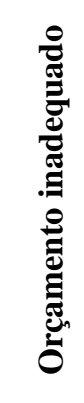 \\
\hline $\begin{array}{c}\text { Assaf e Al-Hejji } \\
\text { (2007) }\end{array}$ & $\mathrm{x}$ & & $\mathrm{X}$ & & & & $\mathrm{x}$ & $\mathrm{x}$ & & $\mathrm{x}$ & & \\
\hline $\begin{array}{c}\text { Frimpong, } \\
\text { Oluwoye e } \\
\text { Crawford (2003) }\end{array}$ & $\mathrm{x}$ & $\mathrm{x}$ & $\mathrm{x}$ & & & & & $\mathrm{x}$ & & & $\mathrm{x}$ & \\
\hline $\begin{array}{c}\text { Odeh e Battaineh } \\
(2002)\end{array}$ & $\mathrm{x}$ & & $\mathrm{x}$ & $\mathrm{x}$ & $\mathrm{x}$ & & & & & & & $\mathrm{x}$ \\
\hline $\begin{array}{l}\text { Oyegoke e Al } \\
\text { Kyumi (2017) }\end{array}$ & $\mathrm{X}$ & $\mathrm{x}$ & & & & $\mathrm{x}$ & & $\mathrm{x}$ & & & $\mathrm{x}$ & \\
\hline $\begin{array}{l}\text { Percentagem de } \\
\text { ocorrencias por } \\
\text { fator }\end{array}$ & $11,9 \%$ & $14,1 \%$ & $13,3 \%$ & $8,1 \%$ & $5,9 \%$ & $8,1 \%$ & $8,1 \%$ & $8,9 \%$ & $1,5 \%$ & $5,2 \%$ & $9,6 \%$ & $5,2 \%$ \\
\hline
\end{tabular}

Como a literatura demonstra, são inúmeros os fatores que podem contribuir para que os empreendimentos possam ser acometidos pelos acréscimos de custo e extrapolação do prazo contratual. Nesse sentido, buscouse, por meio do Quadro 2, realizar uma síntese deles, agrupando-os de forma a generalizar o conteúdo das causas. Cabe destacar os fatores que têm causas relacionadas ao projeto $(14,1 \%)$, ao planejamento $(13,3 \%)$ e ao aspecto financeiro (11,9\%), que são os que aparecem com mais frequência na literatura. No entanto, como afirma Love et al. (2015), seria simplório imaginar que a extrapolação do prazo e do custo é explicada tão somente devido à ocorrência de algumas causas isoladamente, e, sim, que se deve também associá-la à complexidade do processo de entrega de uma obra.

Nesse contexto, percebe-se que os atrasos de obras públicas são recorrentes em vários países nos quais se encontram causas com características semelhantes para a realização de aditivos de prazo de contrato. Esse fato é corroborado pelo trabalho de Maués et al. (2017), que afirmam que esse problema também acontece em países desenvolvidos, devido à existência de problemas estruturantes que levam à ocorrência dos atrasos nas obras. Todavia, há possibilidades de se melhorar o processo de gestão de obras, visando minimizar essas ocorrências, que, entre outros aspectos, acarretam perdas de eficiência e de resultados dos empreendimentos. Esse problema se torna mais grave quando se fala de recursos públicos, pois, além do desperdício, a sociedade não pode usufruir dos serviços e benefícios que as edificações devem oferecer à população.

Como o planejamento de uma obra está diretamente ligado a aspectos relacionados ao custo, prazo e qualidade, os motivos que afetam o prazo de uma obra, por consequência, poderão afetar também seu custo final. Por isso, é importante conhecer o que a literatura aponta sobre as principais causas de alterações nos custos finais das obras, pois a extrapolação de custo é um problema comum da construção (FLYVBJERG; HOLM; BUHL, 2002).

Os fatores mais frequentes apontados pelos autores pesquisados neste trabalho como responsáveis por não se chegar ao resultado de custo inicial previsto em obras por ocasião de sua conclusão foram consolidados no Quadro 2 e apontam para as mesmas causas identificadas nos aditivos de prazo, o que corrobora a pesquisa de Jung, Kim e Lee (2016), que identificaram que problemas relacionados ao projeto, ao planejamento e ao pagamento são as causas mais prováveis do aumento no custo das obras. Entretanto, é importante destacar que, embora um fator específico tenha sido identificado na literatura e apontado com frequência como causa de aumento nos custos, não se pode limitar apenas à busca de eliminar essa causa para resolver o problema. Conforme Adam, Josephson e Lindahl (2017) afirmam em sua pesquisa sobre aditivo de custo em obras 
públicas, nem sempre os fatores que aparecem no ranking entre as causas de aditivos são os que têm maior impacto sobre o excesso de custo ou atrasos de tempo, pois a questão é bastante complexa.

Portanto, o desempenho de projetos em obras públicas é uma medida que reflete a eficiência do trabalho do país e sua capacidade de atingir suas aspirações de desenvolvimento, sendo esse tema objeto de inúmeros estudos, conferências e debates (ALSULIMAN, 2019). Além disso, o tema tem adquirido alta relevância perante a sociedade devido ao incremento significativo no montante de recursos destinados a investimentos nos últimos anos (SIMÕES; PEREIRA, 2012). Porém, estudos apontaram para as dificuldades na execução desses investimentos, atrasos na entrega das obras e estouros de orçamento como os principais efeitos desse problema (GOMIDE; PEREIRA, 2018). Assim, esta pesquisa pretende contribuir explorando uma lacuna do conhecimento em relação aos aditivos de custo e de prazo de obras públicas do setor educacional, mediante um levantamento de dados nacional para avaliar como as regiões do país se comportam na prática da celebração de aditivos contratuais e suas principais causas.

\section{Método de pesquisa}

Para atingir os objetivos da pesquisa, definida como um estudo de caso múltiplo de levantamento exploratório, foi estabelecido o método de acordo com as seguintes etapas:

(a) referencial teórico: foi realizada uma busca na literatura para identificar estudos que abordaram fatores responsáveis pelo não cumprimento de prazos e custos iniciais em obras;

(b) coleta de dados: os dados foram coletados através do Sistema Integrado de Monitoramento Execução e Controle (Simec), que tem seu preenchimento sob responsabilidade do fiscal da obra (servidor do órgão público vinculado ao MEC). Foram coletadas 2.899 obras, e nesse contexto não foi discutido o teor do preenchimento dos dados de cada obra. Desse universo que abrange obras $100 \%$ concluídas com valores acima de R \$ 1.000.000,00 (para evitar que a amostra possuísse obras de reforma e adaptação), foram utilizadas nesta pesquisa 2.178 obras. Além disso, somente obras de universidades federais, institutos federais e hospitais universitários foram consideradas, estas cadastradas no período entre 2006 e 2017, o que abrange o universo de 109 universidades e hospitais universitários em 27 unidades da federação localizados em 460 municípios;

(c) análise de dados quantitativos da pesquisa: inicialmente foi realizada uma análise descritiva dos dados de prazo e custo (previsto e final) dos contratos das obras coletadas, e estes foram transformados em percentuais e analisados estatisticamente, como mostra a Figura 1. Essa análise, como mostra a Figura 1, lançou mão do teste de normalidade, que atestou que os dados (percentuais de aditivos de obras) não são simétricos. Logo, a análise de variância de Kruskal-Wallis é utilizada como alternativa não paramétrica (dados assimétricos) à ANOVA (análise de variância) de um fator. Portanto, o teste Kruskal-Wallis pode ser usado para testar se as medianas das amostras provêm de populações com a mesma distribuição (MARÔCO, 2018). Em seguida, com o teste U de Mann-Whitney, verificou-se que as amostras independentes possuem diferenças significativas em relação a um nível de significância de 0,05. Assim, de posse do resultado do teste, foi possível identificar o comportamento das medianas das regiões em relação a prazo e a custo. Após realizados os testes estatísticos, puderam ser desenvolvidos gráficos com distribuições de frequência, com efeito ilustrativo, para observar em quais faixas de aditivos se observam maiores diferenças entre as regiões.

(d) análise de dados qualitativos da pesquisa: os motivos responsáveis pelas alterações de contratos na amostragem geral foram coletados no Simec. Dentro do sistema, na aba "Contratação", no campo

"Aditivos/Apostilamento", selecionou-se o aditivo de contrato e verificou-se o item "Justificativa". Em seguida, uma planilha com as principais causas de alterações de custo e de prazo, adaptada do estudo de Santos (2015), foi elaborada (Figura 2).

Como mostra a Figura 2, nas obras nas quais foi constatado o lançamento no Simec pelos fiscais, os aditivos foram contabilizadas em uma planilha com os motivos mais frequentes, sua ocorrência (coluna), as obras (linhas) e o percentual de ocorrência. Posteriormente, foram classificados em um ranking de ordem decrescente. Assim, a planilha utilizou o método de classificação ABC, no qual a quantidade de ocorrência de determinada justificativa/fator foi organizada em um ranking, que teve a primeira faixa em $80 \%$ (A), a segunda faixa em 15\% (B), e terceira faixa em 5\% (C). Para essa fase, do total das 2.178 obras, buscaram-se aquelas em que as justificativas de aditivos estavam disponíveis e com as descrições detalhadas no banco de dados do Simec, perfazendo um total de aproximadamente 30 obras por região, sendo 153 obras com aditivos de prazo e 152 com aditivos de custo, totalizando 163 obras amostradas. Portanto, foram utilizados dois bancos de dados: 
(a) um geral (2.178 obras), para diagnosticar os percentuais de aditivos e sua intensidade; e

(b) outro reduzido (163 obras), tratando somente das justificativas de aditivos de prazo e de custo.

Figura 1 - Etapas do tratamento de dados

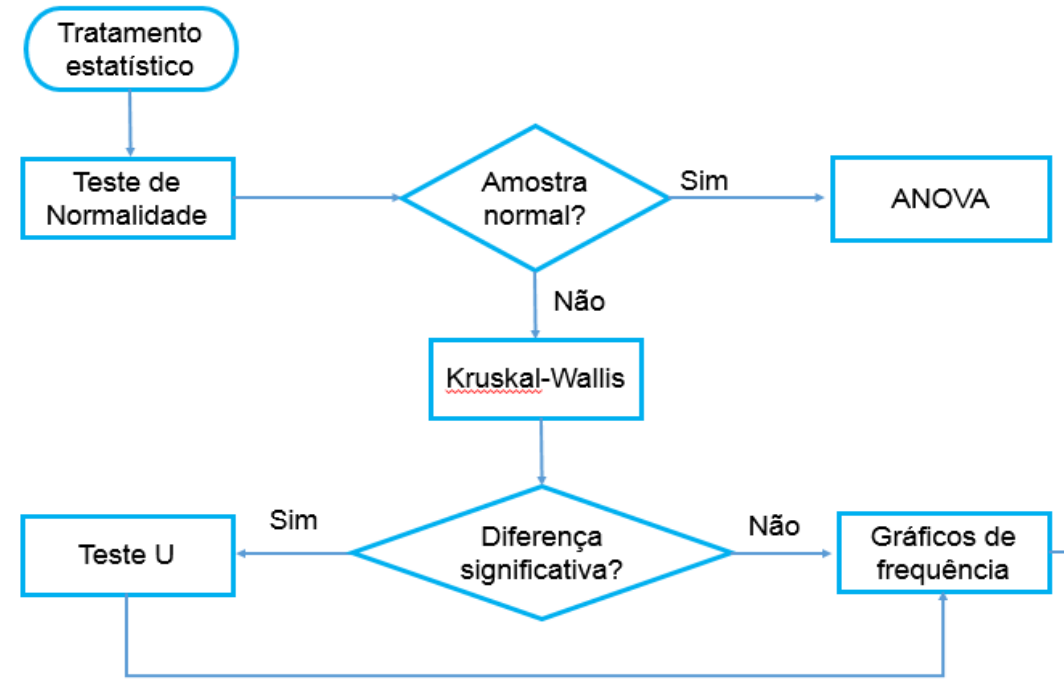

Figura 2 - Captura de trecho da planilha de justificativas de custo

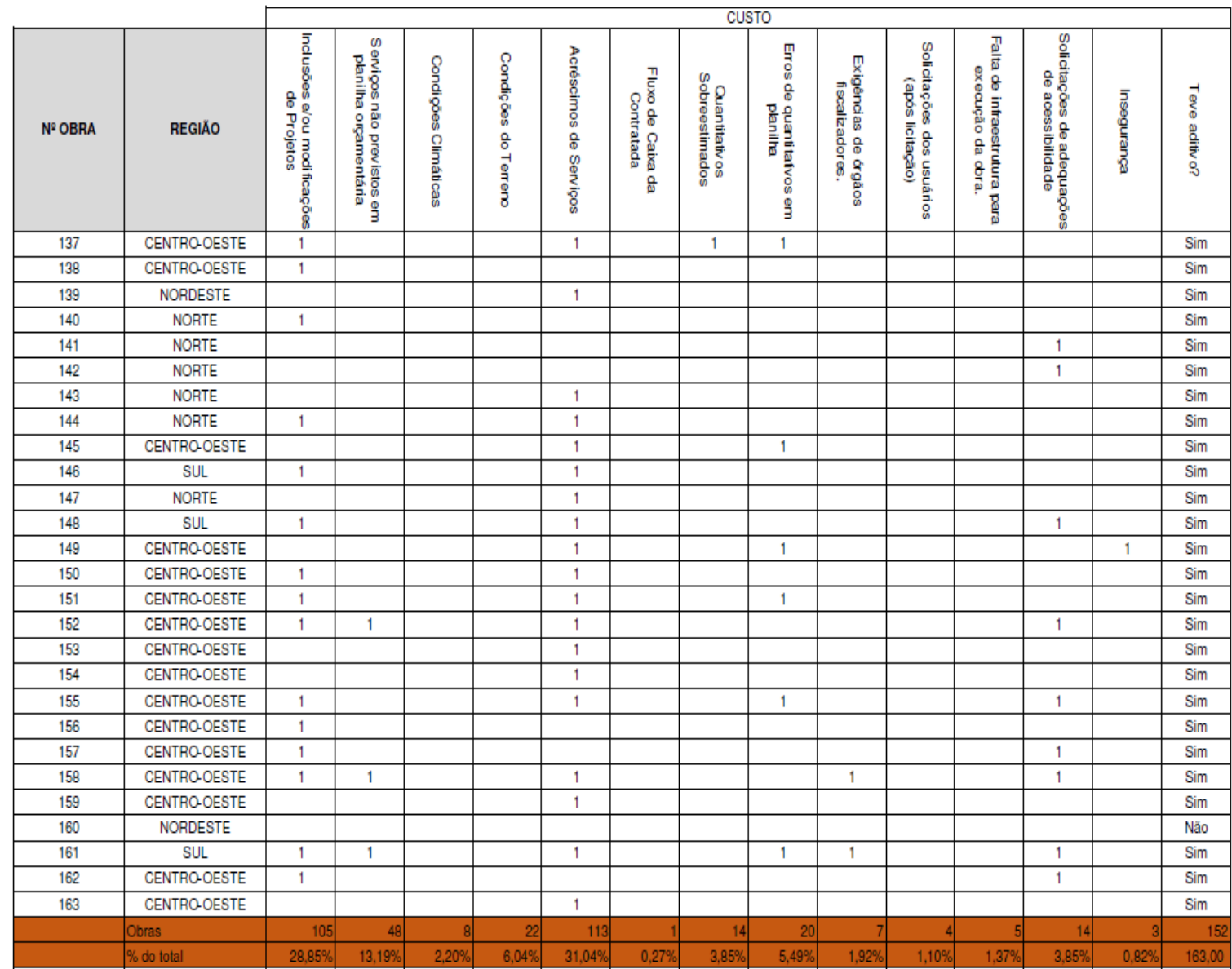


Ressalta-se que as edificações construídas nas Ifes, alvos desta pesquisa, são basicamente constituídas de pavilhões de sala de aula, laboratórios e instalações hospitalares. Essas construções seguem a tendência tradicional na construção brasileira, ou seja, são caracterizadas por fundações profundas, estruturas de concreto armado (moldadas in loco) com as paredes de vedação constituídas em blocos cerâmicos ou de concreto, revestidas de argamassa de cimento e areia, com pisos estruturados e revestidos de cerâmica ou de matérias de alta resistência.

Como visto anteriormente, as obras executadas nas Ifes não têm características diferentes das demais obras públicas de edificações. A escolha desse conjunto de obras ocorreu em função do acesso ao Simec, o que possibilitou extrair as informações pertinentes às obras executadas pelo Ministério da Educação no país.

\section{Resultados e discussões}

\section{Panorama geral dos aditivos de prazo}

A análise de prazo no universo da pesquisa demonstrou que a ausência de um limitador legal leva a uma prática comum de prorrogação de contratos. A Figura 3 apresenta os resultados do diagnóstico geral dos aditivos de prazo, com o percentual de obras que tiveram aditivos de prazo em relação à amostra geral (2.178 obras), bem como a média e a mediana por região.

O primeiro parâmetro observado na Figura 3 foi a quantidade de obras em relação ao total de amostragem que tiveram aditivos de prazo, ou seja, $69,05 \%$ das obras tiveram aditivos de prazo. A região Centro-Oeste teve a maior quantidade de obras nesse quesito $(73,09 \%)$, e a região Nordeste, a menor quantidade de obras com aditivos de prazo $(63,76 \%)$.

Em relação às medidas de centralidade, tem-se a média e a mediana nacionais a 92,03\% e a 70,88\%, tendo a região Centro-Oeste $(123,03 \%$ e $100 \%)$ os resultados menos satisfatórios, e a região Sul (72,96\% e 57,53\%), os resultados mais satisfatórios. Com isso se evidenciam comportamentos mais semelhantes entre as demais regiões e a média nacional; por outro lado, há uma distância maior entre as regiões Sul e Centro-Oeste. Pode-se observar que os contratos tendem a ter próximo do dobro da duração inicialmente prevista em $69,05 \%$ dos casos. Portanto, a ausência de um limitador legal para a quantidade dos aditivos de prazo poderia ser um dos fatores que fazem com que os resultados nesse quesito, se comparado a custo, sejam bem maiores, tal qual ocorreu nos trabalhos de Santos (2015), Rasmussem (2013), Silva (2014), Ribeiro (2015) e Freitas (2017), que fizeram estudos em obras públicas.

Para os acréscimos de prazo que não possuem um limitador legal foram observadas medianas maiores, fomentando a dúvida do pressuposto acima. Para ilustrar essa situação, tem-se que a mediana nacional para aditivos de prazo $(70,88 \%)$ foi 5 vezes maior do que a mediana nacional para custo $(13,87 \%)$, ou seja, o aspecto de prazo de obras públicas é o campo que supostamente tem a maior possibilidade de melhorias e também o mais afetado pelos fatores relacionados aos projetos de construção.

Figura 3 - Diagnóstico geral de prazo

Obras com aditivos, média e mediana de prazo

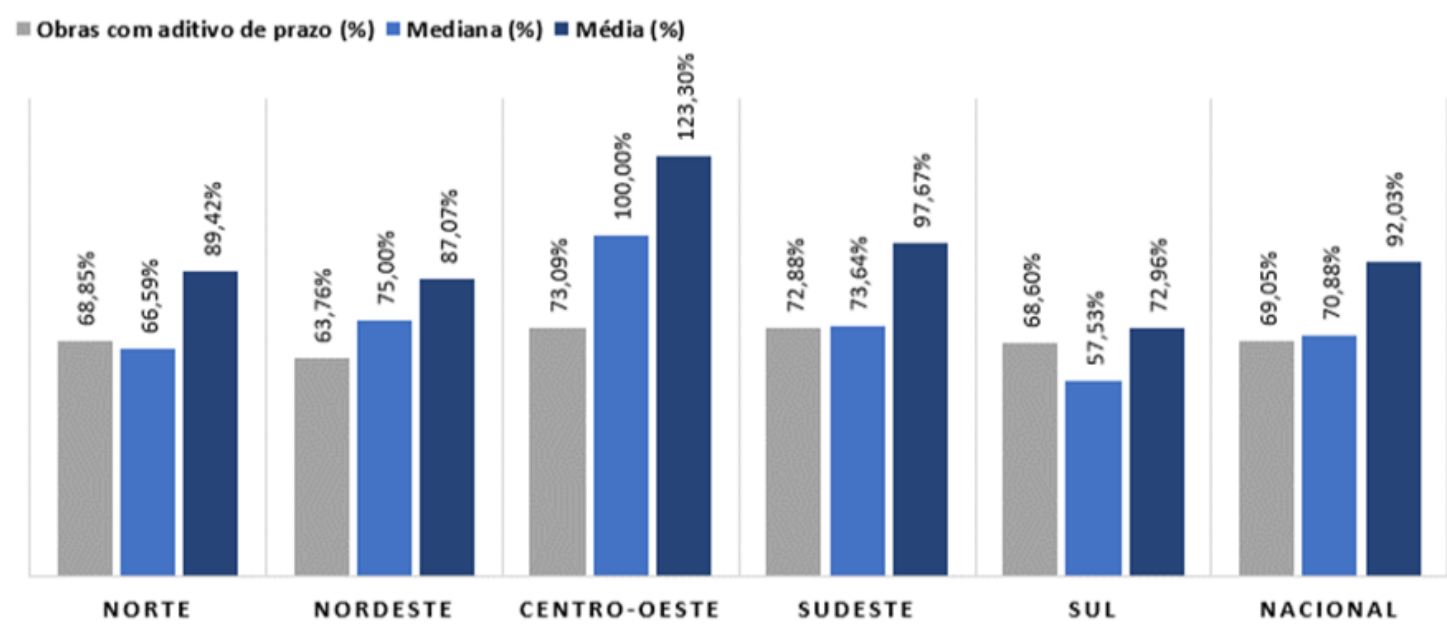


Na sequência do diagnóstico com os aditivos de prazo, o teste de normalidade evidenciou que as amostragens das regiões possuíam dados assimétricos. Assim, procedeu-se ao teste ANOVA de KruskalWallis. Nesse teste, buscou-se identificar quais regiões obtiveram um valor $p<0,05$; atestou-se que há diferença significativa entre as regiões no que diz respeito ao percentual de aditivos. Portanto, para saber exatamente onde estão as diferenças, foi realizado o Teste U de Mann-Whitney nos cruzamentos entre as regiões, conforme se observa na Tabela 1.

Os resultados do Teste $U$, na Tabela 1, evidenciaram que a região Centro-Oeste teve sua amostra com diferenças significativas em um nível de significância de 0,05 em relação a todas as outras regiões. A região Sul, por sua vez, também possui diferenças em relação às demais regiões, com exceção de seu cruzamento com a região Norte. A partir desses dados, entende-se que as regiões com maior e menor medianas apresentaram diferenças significativas em relação às demais regiões. A Figura 4 mostra a distribuição dos dados entre as regiões.

$\mathrm{Na}$ Figura 4, além de notar que todas as regiões possuem alguns pontos isolados, distantes da maior concentração de dados, é possível entender que as regiões Norte, Nordeste e Sudeste apresentaram distribuições próximas, o que sugere um comportamento similar dessas regiões em relação aos percentuais aditivos de prazo de obras. Os pontos fora do box plot elucidam que as distribuições são assimétricas (Figura 5).

A Figura 5 sinaliza que a região Sul, com resultado mais satisfatório em relação aos aditivos de prazo, teve cerca de $65 \%$ de seus aditivos de prazo na faixa que vai até $75 \%$. Ao realizar uma análise das causas relatadas pelos fiscais das obras nessa região, percebeu-se que uma das causas que a diferencia das demais regiões é a baixa ocorrência de aditivos em função:

(a) de problemas financeiros, corroborado pelos autores Aljohani, Ahiaga-Dagbui e Moore (2017), Tipili e Yakubu (2017) e Larsen et al. (2016);

(b) condições inadequadas no canteiro, também apontado por Prasitnok et al. (2017), Muhwezi, Acai e Otim (2014) e Gardezi, Marnavi e Gardezi (2014) como um fator importante para minimizar a dilatação do prazo;

(c) alterações no escopo do contrato, que também foram as razões encontradas em algumas pesquisas, como as de Oyegoke e Al Kyumi (2017) e Sambasivan et al. (2017); e, ainda,

(d) erros decorrentes do orçamento, fato demonstrado pelo pesquisadores Aljohani, Ahiaga-Dagbui e Moore (2017) e El-Ahwal, El-Attar e Abdel-Hafez (2017), que podem contribuir para reduzir os aditivos de custo.

Tabela 1 - Teste U nas amostras de prazo

\begin{tabular}{l|c|c}
\hline \multicolumn{1}{c|}{ Cruzamento } & Valor $\mathbf{~ p}$ & $<\mathbf{0 , 0 5}$ \\
\hline Norte x Nordeste & 0,132372 & Não \\
Norte x Centro-Oeste & 0,000056 & Sim \\
Norte x Sudeste & 0,232681 & Não \\
Norte x Sul & 0,205641 & Não \\
Nordeste x Centro-Oeste & 0,000281 & Sim \\
Nordeste x Sudeste & 0,791369 & Não \\
Nordeste x Sul & 0,000437 & Sim \\
Centro-Oeste x Sudeste & 0,000175 & Sim \\
Centro-Oeste x Sul & 0,000000 & Sim \\
Sudeste x Sul & 0,001700 & Sim \\
\hline
\end{tabular}


Figura 4 - Box plot das obras com aditivos de prazo

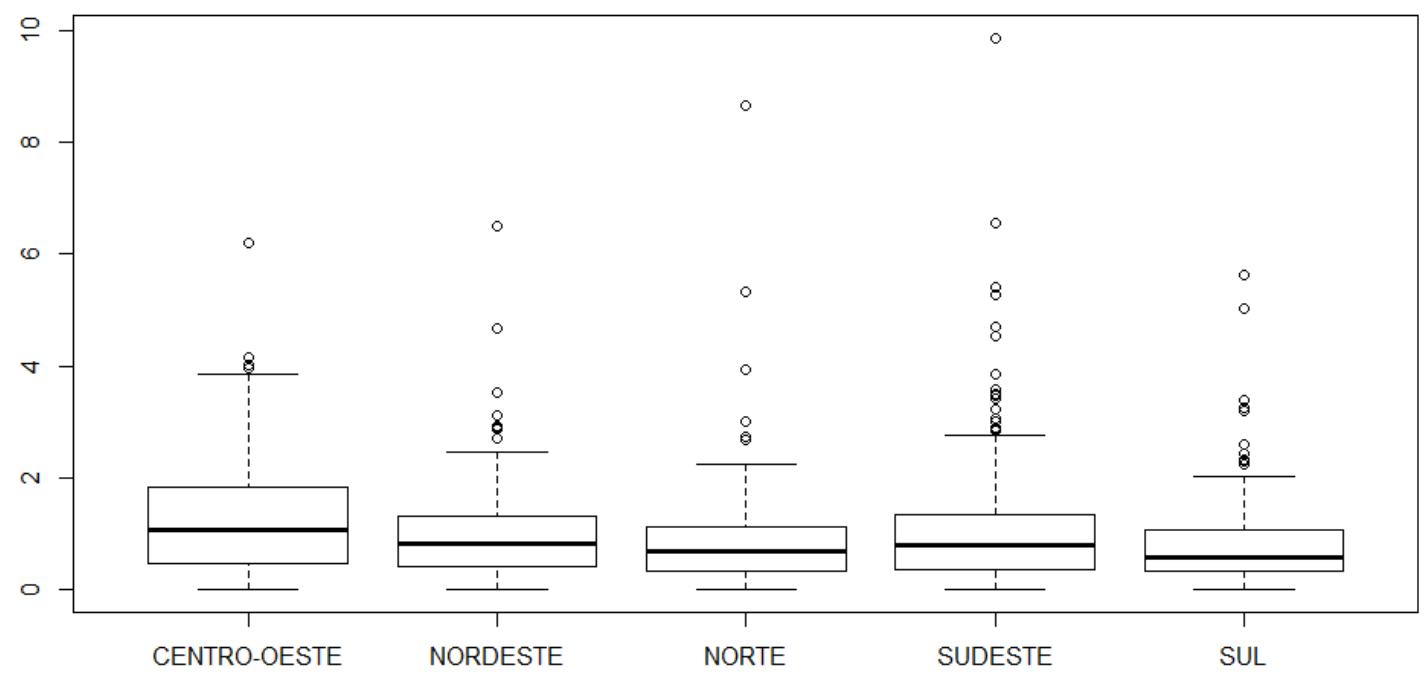

Figura 5 - Distribuição de obras por faixa de aditivos de prazo
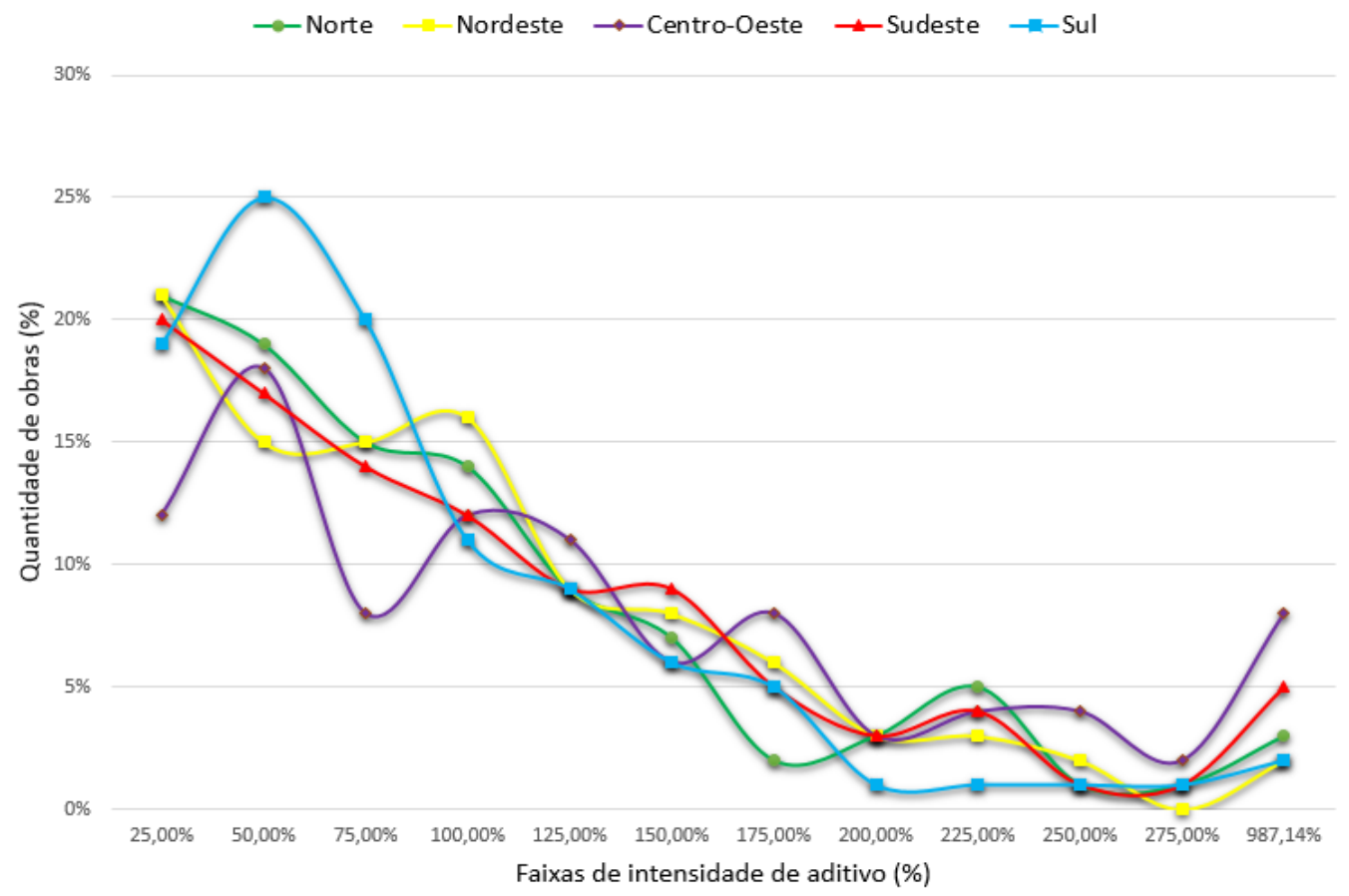

Em contrapartida, a região Centro-Oeste teve apenas 50\% de suas obras na faixa que vai até 100\%, pois foi a região que apresentou os maiores desvios em relação ao prazo inicial. Esse fato foi ocasionado, de acordo com as informações retiradas do Simec, principalmente devido às causas de:

(a) alterações de escopo, causa encontrada também nas pesquisas de Alinaitwe, Apolot e Tindiwensi (2013) e Ricardino, Silva e Alencar (2013);

(b) alterações de projeto, que são apontadas por El-Ahwal, El-Attar e Abdel-Hafez (2017), Tipili e Yakubu (2017) e Larsen et al. (2016) como fontes de aditivos; e, ainda

(c) erros no orçamento, pois isso reflete diretamente na execução da obra, sendo este fato corroborado por pesquisas realizadas por Santos (2015) e Cheng (2014).

Para as regiões Norte, Nordeste e Sudeste, observou-se maior aproximação dos pontos de frequências entre as faixas de aditivos, como na faixa dos $125 \%$, na qual aparecem apenas dois pontos em vez de cinco pontos, 
em função da superposição dos valores de quatro regiões entre as cinco analisadas. Nessas regiões a celebração de aditivos de prazo ocorreram em função das mesmas causas relatas para a região Centro-Oeste, apenas em menor proporção.

Na região Centro-Oeste, que teve os resultados menos satisfatórios, se observa a distribuição de frequência mais elevada após a faixa de $125 \%$, contribuindo para seus resultados acima das medidas centrais nacionais. É possível observar uma concentração em todas regiões, de pontos distantes das médias e medianas, o que mostra alguns casos de obras que tiveram atrasos significativos, sendo os maiores na região Centro-Oeste.

Após a análise dos aditivos de prazos realizados nesta seção e com o intuito de explorar os dados coletados na amostra desta pesquisa, é abordado no item a seguir o contexto sobre os aditivos de custo. Será demonstrado que não possuem uma correlação forte com os resultados de aditivos de prazo em relação a sua intensidade.

\section{Panorama geral de aditivos de custo}

Para a avaliação dos resultados de custo, um histograma foi organizado. Assim, o panorama geral é semelhante ao da distribuição das obras que obtiveram aditivos de prazo, porém os aditivos de custo possuem incidência inferior, logo um quantitativo de obras menor quando comparado aos quantitativos de prazo. A Figura 6 apresenta os resultados relacionados à incidência, mediana e média dos aditivos de custo.

O primeiro ponto a ser observado na Figura 6 é o percentual de obras que tiveram aditivo em cada região e compará-lo com a média nacional. Nesse ponto, afere-se que a região Nordeste $(54,36 \%)$ teve a menor incidência de obras com aditivos, ao passo que a região Sudeste $(67,12 \%)$ teve a maior incidência, acima do percentual nacional $(61,89 \%)$.

Em relação à média e à mediana nacional $(14,86 \%$ e $13,87 \%)$, tem-se a região Centro-Oeste $(17,15 \%$ e $18,42 \%)$ com os resultados menos satisfatórios, e a região Sul $(10,91 \%$ e $9,14 \%)$ com os resultados mais satisfatórios, sendo as regiões mais distantes em pontos percentuais. Por outro lado, as demais regiões tiveram pontos percentuais mais próximos, o que pode ser evidenciado na sequência de tratamentos estatísticos. Observou-se que a presença de um limitador legal para acréscimos de custo em obras públicas traz as médias desses aditivos para um patamar abaixo dos $25 \%$. Esse fato pode contribuir para esse fenômeno, pois essa opinião também é corroborada por outros estudos, como Freitas (2017) e Ribeiro (2015), nos quais os resultados obtidos foram próximos ao limite previsto na legislação.

Na sequência, o teste de normalidade mostrou que os valores de $\mathrm{p}$ das amostras mantiveram-se abaixo do nível de significância de 0,05, confirmando que as distribuições percentuais das regiões não seguem um padrão simétrico. Logo, a execução do teste de Kruskal-Wallis para avaliar as diferenças amostrais tornou-se necessário, e, com efeito, o resultado do teste Kruskal-Wallis com o valor p abaixo do nível de significância de 0,05 aponta que existe diferença significativa entre uma ou mais regiões. Portanto, para saber exatamente onde estão as diferenças, foi realizado o Teste U entre as amostras, cujo resultado é apresentado na Tabela 2.

Figura 6 - Percentual de ocorrência e mediana dos aditivos de custo

Obras com aditivos, média e mediana de custo

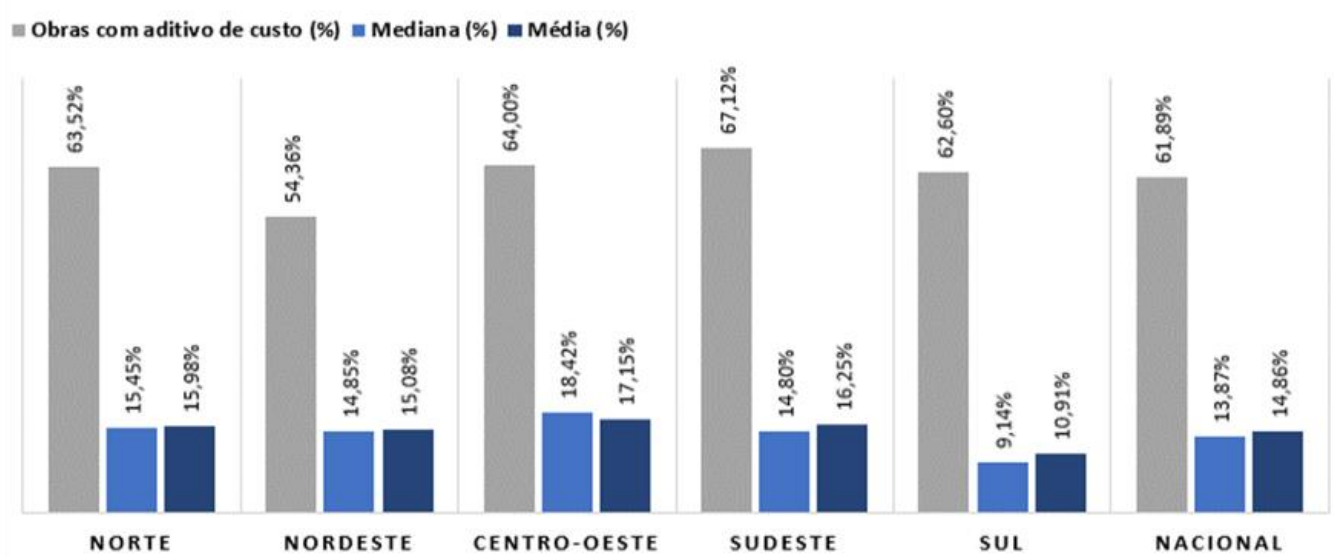


Tabela 2 - Teste U nas amostras de custo

\begin{tabular}{l|c|c}
\hline \multicolumn{1}{c|}{ Cruzamento } & Valor $\mathbf{~}$ & $\mathbf{< 0 , 0 5}$ \\
\hline Norte x Nordeste & 0,222555 & Não \\
Norte x Centro-Oeste & 0,196247 & Não \\
Norte x Sudeste & 0,521289 & Não \\
Norte x Sul & 0,000000 & Sim \\
Nordeste x Centro-Oeste & 0,003461 & Sim \\
Nordeste x Sudeste & 0,475607 & Não \\
Nordeste x Sul & 0,000000 & Sim \\
Centro-Oeste x Sudeste & 0,023511 & Sim \\
Centro-Oeste x Sul & 0,000000 & Sim \\
Sudeste x Sul & 0,000000 & Sim \\
\hline
\end{tabular}

Os resultados da Tabela 2 evidenciam que as principais diferenças confrontam com as regiões Centro-Oeste e Sul, porém se nota que o cruzamento entre as regiões Centro-Oeste e Norte não obteve diferença significativa. Além disso, a região Sul obteve diferença significativa em relação a todas as demais regiões, diferentemente da análise de prazo, em que seu cruzamento com a região Norte não apresentou diferenças significativas. Conclui-se que as regiões com maior (Centro-Oeste) e menor (Sul) medianas representaram as diferenças mais significativas, e, mais uma vez, as regiões Norte, Nordeste e Sudeste obtiveram comportamento estatisticamente semelhante em relação aos percentuais de aditivos.

O box plot apresentado na Figura 7 mostra a distribuição de amostragem dos percentuais dos aditivos de custo em cada região, ilustrando uma visão geral das amplitudes das amostras.

Na Figura 7 nota-se que a região Sudeste possui mais pontos fora do box plot, indicando que houve algumas obras que contribuíram para o aumento de sua média. A região Sul é a que menos se assemelha às demais, elucidando o resultado do Teste $\mathrm{U}$; em contrapartida, percebe-se que a região Norte se encaixa com as demais, inclusive com a região Centro-Oeste, que obteve diferenças significativas em relação às outras regiões. Na Figura 8 é possível observar que as regiões Norte, Nordeste e Sudeste apresentam maiores similaridades também em relação às amostragens de prazo. A distribuição de frequência na Figura 8 ilustra as diferenças entre as faixas de aditivos.

A distribuição de frequências dos aditivos de custo das regiões apresentada na Figura 8 aponta claramente para o comportamento distinto dos percentuais de aditivos da região Sul, os quais concentraram 50\% de seus resultados até a mediana de $9,14 \%$, ou seja, até a faixa de $10 \%$ de aditivos. Para melhor compreender essa taxa reduzida no volume total de aditivos de custo da região, buscou-se extrair das respostas da fiscalização lançadas no sistema Simec quais as causas que favoreceram esse resultado. Pode-se destacar redução devido a:

(a) poucas alterações nas características do projeto solicitadas pelos usuários, ou seja, mudanças no projeto, o que também foi apontado pelas pesquisas realizadas por Muhwezi, Acai e Otim (2014) e Alinaitwe, Apolot e Tindiwensi (2013);

(b) ausência de problemas no fluxo financeiro da obra, garantindo os recursos para a execução dos serviços em tempo hábil, um fator importante ressaltado nas pesquisas de Larsen et al. (2016) e Gardezi, Marnavi e Gardezi (2014); e

(c) aumento do diálogo com a redução de problemas devido ao contratante público, possibilitando maior segurança na relação contratual - esse aspecto também pode ser observado nas pesquisas de Sambasivan $e t$ al. (2017) e Santos (2015).

As regiões Nordeste e Sudeste tiveram comportamento bastante semelhante quando se analisa a maior concentração de obras que se deu na faixa entre $5 \%$ e $25 \%$ de aditivos de custo. Essas regiões também encontram causas semelhantes que resultaram em aditivos, sendo estes próximos da média nacional:

(a) problemas no orçamento, causa corroborada por pesquisas realizadas por Cheng (2014) e Marzouk e ElRasas (2014);

(b) adequação de projetos, especialmente devido à acessibilidade, nas pesquisas de Larsen et al. (2016) e

Doloi et al. (2012); e 
(c) condições de trabalho no canteiro, ou seja, disponibilidade de água, energia e segurança de maneira adequada, causa relatada também nos trabalhos de Prasitnok et al. (2017), Yang e Ou (2008) e Alaghbari et al. (2007).

A região Centro-Oeste, que obteve a média e a mediana de aditivos mais altas, mostrou a maior concentração de obras nas faixas que vão de $20 \%$ a $95 \%$, o que contribuiu para a elevação das médias de aditivos na região, fato esse ocorrido em função das causas de:

(a) modificações no projeto;

(b) aumento de serviço em decorrência das mudanças no projeto; e

(c) erros na planilha orçamentária.

Todas essas já tinham sido também relacionadas como causas de aditivos de prazo na mesma região. Constata-se que o comportamento das distribuições dos dados em sua amostragem se distinguiu principalmente da região Sul, além de ter diferenças em relação às demais regiões.

Figura 7 - Box plot dos aditivos de custo

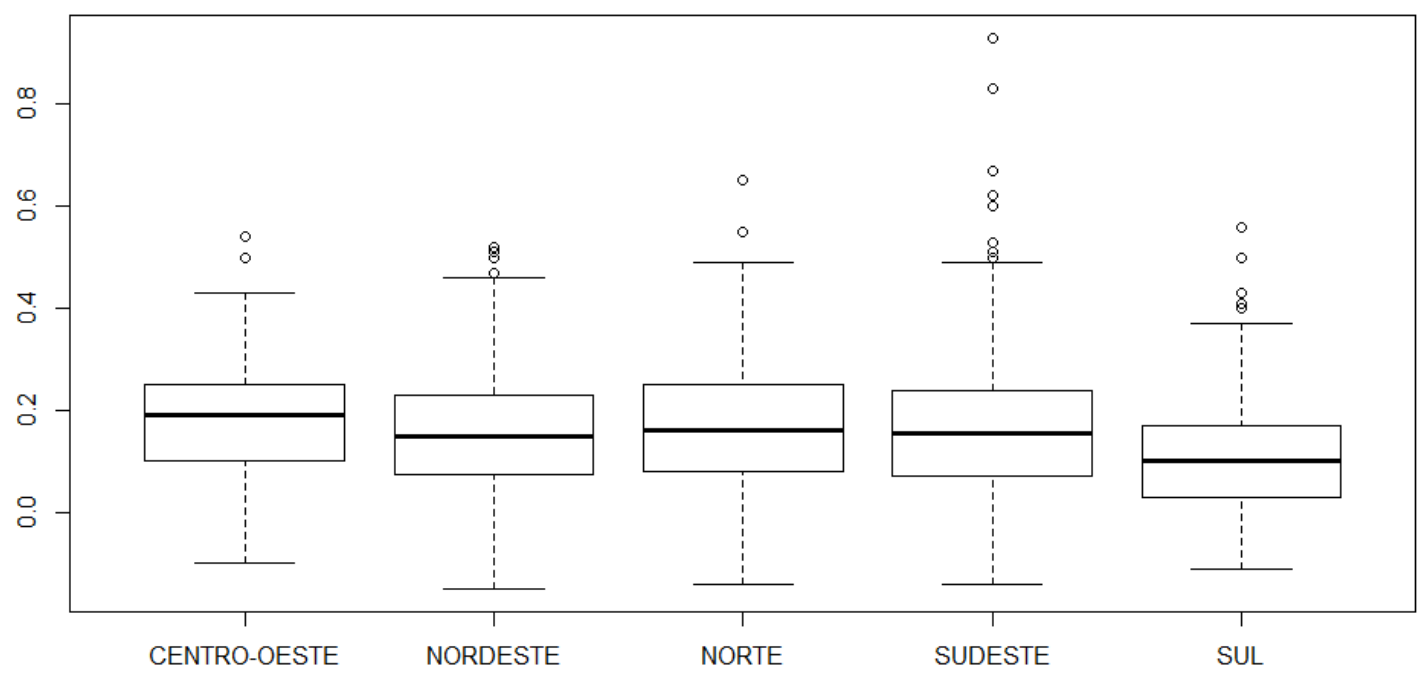

Figura 8 - Distribuição de obras por faixas de aditivos de custo

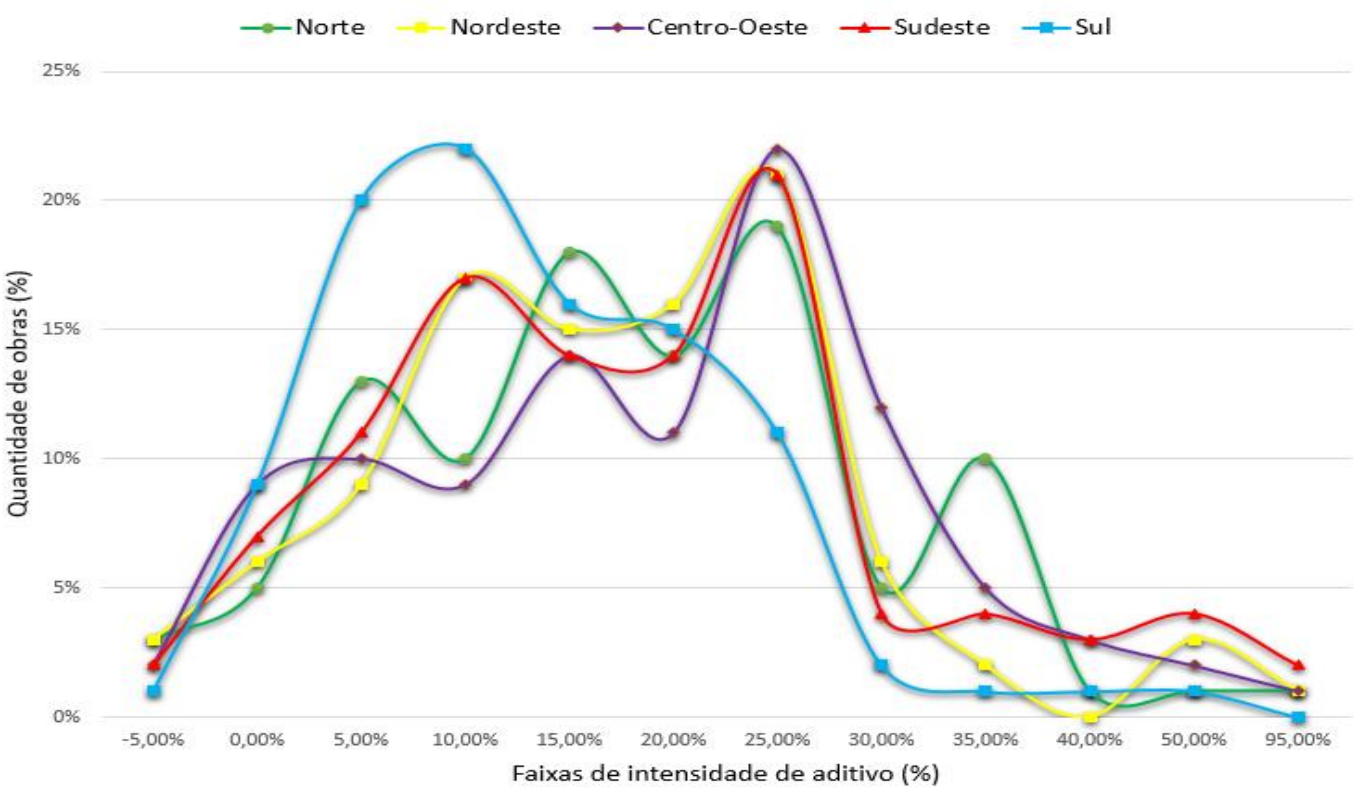


Os resultados mostram que as principais diferenças confrontam com as regiões Centro-Oeste e Sul, porém se nota que o cruzamento entre as regiões Centro-Oeste e Norte não obteve diferença significativa. Além disso, a região Sul obteve diferença significativa em relação a todas as demais regiões, diferentemente da análise de prazo, em que seu cruzamento com a região Norte não apresentou diferenças significativas. Conclui-se disso que as regiões com maior (Centro-Oeste) e menor (Sul) medianas representaram as diferenças mais significativas e que, mais uma vez, as regiões Norte, Nordeste e Sudeste obtiveram comportamento estatisticamente semelhante em relação aos percentuais de aditivos. Passado pelo diagnóstico geral das porcentagens de aditivos de custo e de prazo, é necessário entender por que eles ocorrem, na visão dos fiscais de obras das instituições.

\section{Análise das justificativas dos aditivos de prazo e de custo Prazo}

Os principais fatores justificados como causadores de alterações de prazo giram em torno, principalmente, das modificações de projetos, fator este que ao longo da pesquisa se mostrou como um agregador de muitos outros fatores. Com isso, apresenta-se o ranking com os fatores apontados nas justificativas para celebração de aditivos de prazo, representação mostrada na Tabela 3. Ressalta-se que essas informações são de responsabilidade dos fiscais das Ifes e que foram extraídas do Simec.

A partir da Tabela 3 compreende-se que as inclusões e/ou modificações de projetos provocam uma reação em cadeia, por isso o cuidado de tentar levantar certo desmembramento de motivos que estão relacionados direta ou indiretamente com os projetos. Portanto, houve obras que tiveram aditivos devido às modificações de projetos que desencadearam acréscimos de serviços decorrentes das condições encontradas no terreno. Cabe agora apresentar os fatores que foram mais frequentes nas justificativas de custo.

\section{Tabela 3 - Fatores do ranking da classificação ABC de prazo}

\begin{tabular}{|c|c|c|c|c|c|}
\hline $\mathbf{N}^{\mathbf{0}}$ & Fatores de influência em aditivos de prazo & Obras & $\%$ Geral & \% Acumulado & Faixa \\
\hline 1 & Inclusões e/ou modificações de projetos & 114 & $25,56 \%$ & $25,56 \%$ & \multirow{7}{*}{ A } \\
\hline 2 & Acréscimos de serviços & 102 & $22,87 \%$ & $48,43 \%$ & \\
\hline 3 & Condições climáticas & 47 & $10,54 \%$ & $58,97 \%$ & \\
\hline 4 & Logística de materiais e equipamentos & 27 & $6,05 \%$ & $65,02 \%$ & \\
\hline 5 & Condições do terreno & 25 & $5,61 \%$ & $70,63 \%$ & \\
\hline 6 & Atraso na execução de serviços & 22 & $4,93 \%$ & $75,56 \%$ & \\
\hline 7 & Escassez de mão de obra & 19 & $4,26 \%$ & $79,82 \%$ & \\
\hline 8 & Adequações de acessibilidade & 13 & $2,91 \%$ & $82,74 \%$ & \multirow{8}{*}{ B } \\
\hline 9 & Serviços com mão de obra especializada & 11 & $2,47 \%$ & $85,20 \%$ & \\
\hline 10 & $\begin{array}{l}\text { Paralização ou diminuição de ritmo por ordem } \\
\text { da administração }\end{array}$ & 8 & $1,79 \%$ & $87,00 \%$ & \\
\hline 11 & Atraso na aprovação/liberação de projetos & 8 & $1,79 \%$ & $88,79 \%$ & \\
\hline 12 & Atraso na aprovação de aditivos & 8 & $1,79 \%$ & $90,58 \%$ & \\
\hline 13 & $\begin{array}{l}\text { Exigências de órgãos fiscalizadores (Ministério } \\
\text { Público, Corpo de Bombeiros, etc.) }\end{array}$ & 6 & $1,35 \%$ & $91,93 \%$ & \\
\hline 14 & $\begin{array}{l}\text { Fatos imprevisíveis e estranhos à vontade das } \\
\text { partes }\end{array}$ & 6 & $1,35 \%$ & $93,27 \%$ & \\
\hline 15 & Insegurança & 5 & $1,12 \%$ & $94,39 \%$ & \\
\hline 16 & Embargos, acidentes, interdições, greves & 5 & $1,12 \%$ & $95,52 \%$ & \multirow{9}{*}{$\mathrm{C}$} \\
\hline 17 & $\begin{array}{l}\text { Demora na liberação da obra por parte da } \\
\text { administração }\end{array}$ & 4 & $0,90 \%$ & $96,41 \%$ & \\
\hline 18 & Alterações no cronograma & 3 & $0,67 \%$ & $97,09 \%$ & \\
\hline 19 & $\begin{array}{l}\text { Falta de infraestrutura para execução da obra } \\
\text { (água, energia, etc.) }\end{array}$ & 3 & $0,67 \%$ & $97,76 \%$ & \\
\hline 20 & Solicitações dos usuários (após licitação) & 3 & $0,67 \%$ & $98,43 \%$ & \\
\hline 21 & Atraso para início da obra & 3 & $0,67 \%$ & $99,10 \%$ & \\
\hline 22 & Cronograma inadequado & 2 & $0,45 \%$ & $99,55 \%$ & \\
\hline 23 & Mão de obra ineficaz & 1 & $0,22 \%$ & $99,78 \%$ & \\
\hline 24 & Atrasos nos repasses financeiros & 1 & $0,22 \%$ & $100,00 \%$ & \\
\hline
\end{tabular}




\section{Custo}

Os fatores que impactaram no custo das obras foram praticamente os mesmos que impactaram no prazo, haja vista o fato de a maioria dos aditivos ser de prazo e de custo. Com isso, apenas fatores como serviços não previstos em planilha orçamentária, erros de quantitativos em planilha e quantitativos sobrestimados foram destacados para ter uma noção melhor da qualidade dos orçamentos elaborados para a contratação dos empreendimentos. A Tabela 4 apresenta o ranking dos motivos mais mencionados como causadores de aditivos de custo. Ressalta-se que essas informações são de responsabilidade dos fiscais das Ifes e que foram extraídas do Simec.

Na faixa A da classificação de custo, uma diferença que se nota entre os quatro principais fatores dela em relação aos que afetaram o prazo é que os acréscimos de serviços são a principal causa da realização dos aditivos de custo de obras em universidades federais. Porém, quase em sua totalidade, estão relacionados diretamente às inclusões e/ou modificações de projeto que ficaram em segundo lugar. Logo, os esforços devem ser direcionados para a evolução das atividades de projetos em obras públicas.

\section{Conclusão}

O objetivo deste trabalho foi diagnosticar os aditivos contratuais celebrados em obras públicas das instituições federais de ensino superior, tendo sido possível observar que as regiões Sul (com menor amplitude) e Centro-Oeste (com maior amplitude) se destacaram em relação às médias nacionais, a primeira positivamente e a segunda negativamente em relação à realização de aditivos nas obras. Pode-se também identificar que os principais motivos usados como justificativas para a celebração de aditivos foram provenientes de acréscimos de serviços, inclusões e/ou modificações de projetos, serviços não previstos em planilha orçamentária e condições do terreno.

Este estudo contribuiu ainda para identificar se o aspecto regional diferencia a ocorrência e a intensidade de celebração de aditivos nos contratos de obras públicas do setor educacional. Além disso, serviu para avaliar de maneira macro os resultados das obras públicas no âmbito do MEC em torno de custo e de prazo final de obra. Assim, foi possível obter um diagnóstico nacional em aditivos de prazo e de custo de obras públicas.

Após a análise estatística dos percentuais de aditivos de prazo e de custo entre as regiões, observou-se que existe diferença entre as regiões Sul e Centro-Oeste em relação às médias de acréscimos de prazo e de custo em obras de instituições federais de ensino superior. Durante a coleta de dados, foi observado que nos estados da região Sul há melhor preenchimento de dados no sistema, o que pode apontar para um controle maior por parte dos fiscais da instituição, além de um entrosamento maior entre os usuários finais (docentes e técnicos) e os profissionais que atuam na gestão dos contratos das obras.

Tabela 4 - Fatores do ranking da classificação $A B C$ de custo

\begin{tabular}{c|l|c|c|c|c}
\hline $\mathbf{N}^{\mathbf{0}}$ & Fatores de influência em aditivos de custo & Obras & \% Geral & \% Acumulado & Faixa \\
\hline 1 & Acréscimos de serviços & 113 & $31,04 \%$ & $31,04 \%$ & \\
2 & Inclusões e/ou modificações de projetos & 105 & $28,85 \%$ & $59,89 \%$ & \\
3 & Serviços não previstos em planilha orçamentária & 48 & $13,19 \%$ & $73,08 \%$ & $\mathrm{~A}$ \\
4 & Condições do terreno & 22 & $6,04 \%$ & $79,12 \%$ & \\
\hline 5 & Erros de quantitativos em planilha & 20 & $5,49 \%$ & $84,62 \%$ & \\
6 & Quantitativos sobrestimados & 14 & $3,85 \%$ & $88,46 \%$ & $\mathrm{~B}$ \\
7 & Solicitações de adequações de acessibilidade & 14 & $3,85 \%$ & $92,31 \%$ & \\
8 & Condições climáticas & 8 & $2,20 \%$ & $94,51 \%$ & \\
\hline \multirow{2}{*}{9} & Exigências de órgãos fiscalizadores (Ministério & & & & \\
& Público, Bombeiros, etc.) & 7 & $1,92 \%$ & $96,43 \%$ & \\
10 & Falta de infraestrutura para execução da obra & & & & \\
& (água, energia, etc.) & 5 & $1,37 \%$ & $97,80 \%$ & $\mathrm{C}$ \\
11 & Solicitações dos usuários (após licitação) & 4 & $1,10 \%$ & $98,90 \%$ & \\
12 & Insegurança & 3 & $0,82 \%$ & $99,73 \%$ & \\
13 & Fluxo de caixa da contratada & 1 & $0,27 \%$ & $100,00 \%$ & \\
\hline
\end{tabular}


Apesar das diferenças regionais, a celebração de aditivos se mostrou uma prática comum, e os resultados, de modo geral, enfatizam a alta intensidade de alterações nos prazos e custos de obras educacionais no Brasil. Quando comparado a trabalhos internacionais, observa-se que não há um padrão de comportamento que possa servir de parâmetro para a obtenção de uma média nos adicionais de custos e de prazo; estes irão variar de acordo com as características das obras, bem como pela forma na qual o ciclo da obra é considerado.

No entanto, foi possível identificar que as alterações no projeto foram as principais causas de aditivos de prazo (em 75\% dos contratos), e o acréscimo de serviço, a causa majoritariamente identificada para os aditivos de custo (com 74\% dos contratos), mas é importante ressaltar que essas duas causas estão nos dois primeiros lugares tanto nos aditivos de prazo quanto nos de custo, apenas alternado sua posição no ranking. Pode-se com esta pesquisa afirmar que a combinação dessas duas causas é a maior responsável pela celebração de aditivos em obras das Ifes.

Este trabalho também contribuiu na identificação dos fatores com a maior possibilidade de implantação de avanços para o setor educacional de obras públicas federais. Além disso, abriu a possiblidade de ideias para a continuação de pesquisas e estudos nessa área. Como sugestão, pode-se avaliar os processos de elaboração de projetos e fiscalização de obras nas regiões Sul e Centro-Oeste, identificando possíveis fatores que levam a diferentes percentuais dos resultados em relação aos aditivos de obras. Outra sugestão pauta-se em estudar o custo por metro quadrado de construção nas diferentes regiões, dependendo da finalidade da edificação (sala de aula, laboratório ou hospital), para saber se existem diferenças significativas entre as regiões e se elas se relacionam com os resultados de custo e de prazo apresentados nesta pesquisa, assim como verificar como a implantação do BIM poderia influenciar na melhoria do desempenho do processo de licitação pública.

\section{Referências}

ABD EL-RAZEK, M. E.; BASSIONI, H. A.; MOBARAK, A. M. Causes of delay in building construction projects in Egypt. Journal of Construction Engineering and Management, v. 134, n. 11, p. 831-841, nov. 2008.

ADAM, A.; JOSEPHSON, P. B.; LINDAHL, G. Aggregation of factors causing cost overruns and time delays in large public construction projects: trends and implications. Engineering, Construction and Architectural Management, Florida, v. 24, n. 3, p. 393-406, May 2017.

AHIAGA-DAGBUI, D. D. et al. Spotlight on construction cost overrun research: superficial, replicative and stagnated. In: ASSOCIATION OF RESEARCHERS IN CONSTRUCTION MANAGEMENT ANNUAL CONFERENCE, 31., Lincoln, 2015. Proceedings [...] Lincoln: ARCOM, 2015.

AHSAN, K.; GUNAWAN, I. Analysis of cost and schedule performance of international development projects. International Journal of Project Management, v. 28, n. 1, p. 68-78, jan. 2010.

AL-HAZIM, N.; SALEM, Z. A.; AHMAD, H. Delay and cost overrun in infrastructure projects in Jordan. Procedia Engineering, v. 182, p. 18-24, 2017.

AL-KHARASHI, A.; SKITMORE, M. Causes of delays in Saudi Arabian public sector construction projects. Construction Management and Economics, v. 27, n.1, p. 3-23, 2009.

ALAGHBARI, W. et al. The significant factors causing delay of building construction projects in Malaysia. Engineering, Construction and Architectural Management, v. 14, n. 2, p. 192-206, mar. 2007.

ALINAITWE, H.; APOLOT, R.; TINDIWENSI, D. Investigation into the causes of delays and cost overruns in Uganda's public sector construction projects. Journal of Construction in Developing Countries, Penang, v. 18, n. 2, p. 33-47, 2013.

ALJOHANI, A.; AHIAGA-DAGBUI, D.; MOORE, D. Construction projects cost overrun: what does the literature tell us? International Journal of Innovation, Management and Technology, v. 8, n. 2, p. 137 143, apr. 2017.

ALNUAIMI, A. S.; MOHSIN, M. Causes of delay in completion of construction projects in Oman. In: INTERNATIONAL CONFERENCE ON INNOVATIONS IN ENGINEERING AND TECHNOLOGY, 2013, Bangkok, 2013. Proceedings [...] Bangkok: IIE, 2013.

ALSUlimAN, J. A. Causes of delay in Saudi public construction projects. Alexandria Engineering Journal, v. 58, n. 2, p. 801-808, jun. 2019. 
ALTOUNIAN, C. S. Obras públicas: licitação, contratação, fiscalização e utilização. 5. ed. Belo Horizonte: Fórum, 2016.

ARAGÃO, F. A. M. O regime diferenciado de contratações na INFRAERO. São Paulo, 2015. 92 f. Dissertação (Mestrado em Gestão e Políticas Públicas) - Escola de Administração de Empresas de São Paulo, Fundação Getúlio Vargas, São Paulo, 2015.

ASSAF, S. A.; AL-HEJII, S. Causes of delay in large construction projects. International Journal of Project Management, v. 24, n. 4, p. 349-357, 2007.

AZIZ, R. F.; ABDEL-HAKAM, A. A. Exploring delay causes of road construction projects in Egypt. Alexandria Engineering Journal, v. 55, n. 2, p. 1515-1539, jun. 2016.

BRASIL. Lei no 8.666, de 21 de junho de 1993. Institui normas para licitações e contratos da Administração Pública, e dá outras providências. Diário Oficial da União, Brasília, 22 jun. 1993. Disponível em: http://www.planalto.gov.br/ccivil_03/leis/18666cons.htm. Acesso em: 2 fev. 2018.

CHENG, Y. An exploration into cost-influencing factors on construction projects. International Journal of Project Management, Princes Risboroughv, v. 32, n. 5, p. 850-860, jul. 2014.

COUTO, J. P.; TEIXEIRA, J. M. C. As consequências do incumprimento dos prazos para a competitividade da indústria de construção: razões para os atrasos. In: CONFERÊNCIA ENGENHARIA, 3., Covilhã, 2005. Anais [...] Covilhã: UBI, 2005.

CRUZ, H. M.; SANTOS, D. G.; MENDES, L. A. Causas da variabilidade do tempo de execução dos processos em diferentes sistemas construtivos. Ambiente Construído, Porto Alegre, v. 18, n. 1, p. 49-65, jan./mar. 2018 .

DOLOI, H. et al. Analysing factors affecting delays in Indian construction projects. International Journal of Project Management, Princes Risboroughv, v. 30, n. 4, p. 479-489, may 2012.

EL-AHWAL, M.; EL-ATTAR, S.; ABDEL-HAFEZ, W. Factors leading to cost overrun occurrence in construction projects. Port-Said Engineering Research Journal, Port Said, v. 20, n. 1, p. 71-77, 2017.

FILIPPI, G. A.; MELHADO, S. B. um estudo sobre as causas de atrasos de obras de empreendimentos imobiliários na região metropolitana de São Paulo. Ambiente Construído, Porto Alegre, v. 15, n. 3, p. 161173, jul./set. 2015

FLYVBJERG, B.; HOLM, M. K. S.; BUHL, S. L. What causes cost overrun in transport infrastructure projects? Transport Reviews, v. 24, n. 1, p. 3-18, jan. 2004.

FLYVBJERG, B.; HOLM, M. S.; BUHL, S. Underestimating costs in public works projects: Error or lie? Journal of the American Planning Association, v. 68, n. 3, p. 279-295, 2002.

FREITAS, L. A. Levantamento de aumento do custo e do prazo de obras públicas nos últimos sete anos. Brasília, 2017. 70 f. Trabalho de Conclusão de Curso (Graduação em Engenharia Civil) - Faculdade de Tecnologia, Universidade de Brasília, Brasília, 2017.

FRIMPONG, Y.; OLUWOYE, J.; CRAWFORD, L. Causes of delay and cost overruns in construction of groundwater projects in a developing countries: Ghana as a case study. International Journal of Project Management, v. 21, n. 5. P. 321-326, 2003.

GARDEZI, S. S. S.; MANARVI, I. A.; GARDEZI, S. J. S. Time extension factors in construction industry of Pakistan. Procedia Engineering, v. 77, p. 196-204, 2014.

GOMIDE, A. A.; PEREIRA, A. K. (org.). Condicionantes institucionais à execução do investimento em infraestrutura: achados e recomendações. Brasília, DF: IPEA, 2018.

GUNDUZ, M.; NIELSEN, Y.; OZDEMIR, M. Fuzzy assessment model to estimate the probability of delay in Turkish construction projects. Journal of Management in Engineering, Virginia, v. 31, n. 4, p. 14, jul. 2015.

INSTITUTO BRASILEIRO DE GEOGRAFIA E ESTATÍSTICA. PAIC 2016: participação das obras de infraestrutura no valor da indústria da construção cai de 41,3\% para 29,5\% em dez anos. Agência de Notícias, Rio de Janeiro, 2018. Disponível em: https://agenciadenoticias.ibge.gov.br/agencia-sala-deimprensa/2013-agencia-de-noticias/releases/21372-paic-2016-participacao-das-obras-de-infraestrutura-novalor-da-industria-da-construcao-cai-de-41-3-para-29-5-em-dez-anos. Acesso em: 8 out. 2018. 
JUNG, J. H.; KIM, D. Y.; LEE, H. K. The computer-based contingency estimation through analysis cost overrun risk of public construction project. KSCE Journal of Civil Engineering, v. 20, n. 4, p. 1119-1130, 2016.

LARSEN, J. K.; SHEN, G. Q.; LINDHARD, S. M. Factors affecting schedule delay, cost overrun, and quality level in public construction projects. Journal of Management in Engineering, v. 32, n. 1, p. 1-10, 2016.

LARSEN, J. K. et al. Factors affecting schedule delay, cost overrun, and quality level in public construction projects. Journal of Management in Engineering, Virginia, v. 32, n. 1, p. 1-29, jan. 2016.

LOVE, P. E. D. et al. Determining the probability of project cost overruns. Journal of Construction Engineering and Management, v. 139, n. 3, p. 321-330, Mar. 2013.

LOVE, P. E. D. et al. Understanding the landscape of overruns in transport infrastructure projects. Environment and Planning B: Planning and Design, v. 42, n. 3, p. 490-509, jan. 2015.

MAHAMID, I. Common risks affecting time overrun in road construction projects in Palestine: Contractors' perspective. Australasian Journal of Construction Economics and Building, v. 13, n. 2, p. 45-53, jun. 2013.

MAHAMID, I.; BRULAND, A.; DMAIDI, N. Causes of delay in road construction projects. Journal of Management in Engineering, Virginia, v. 28, n. 3, p. 300-310, 2011.

MARÔCO, J. Análise estatística com o SPSS Statistics. 7. ed. Pêro Pinheiro: Report Number, 2018.

MARZOUK, M. M.; EL-RASAS, T. I. Analyzing delay causes in Egyptian construction projects. Journal of Advanced Research, v. 5, n. 1, p. 49-55, jan. 2014.

MATTOS, C. Modalidade de licitação e cartéis no Brasil. Brasília: Câmara dos Deputados, 2014.

MAUÉS, L. M. F. et al. Construction delays: a case study in the Brazilian Amazon. Ambiente Construído, Porto Alegre, v. 17, n. 3, p. 167-181, jul./set. 2017.

MAUÉS, L. M. F. et al. Construction duration predictive model based on factorial analysis and fuzzy logic. Ambiente Construído, Porto Alegre, v. 19, n. 4, p. 115-133, out./dez. 2019.

MONTEIRO, M. O. Processos de obras de infra-estruturas viárias municipais: uma análise dos desvios de custo e de prazo. Vila Real, 2010. 180 f. Dissertação (Mestrado em Engenharia e Planejamento Municipal) - Universidade de Trás-os-Montes e Alto Douro, Vila Real, 2010.

MOURA, H. M. P.; TEIXEIRA, J. M. C. Competitividade e incumprimento das funções de gestão da construção. In: CONGRESSO CONSTRUÇÃO, 3., Coimbra, 2007. Anais [...] Coimbra: Universidade de Coimbra, 2007.

MUHWEZI, L.; ACAI, J.; OTIM, G. An assessment of the factors causing delays on building construction projects in Uganda. Construction Engineering and Management, Virginia, v. 3, n. 1, p. 13-23, mar. 2014.

ODEH, A. M.; BATTAINEH, H. T. Causes of construction delay: traditional contracts. International Journal of Project Management, v. 20, n. 1, p. 67-73, 2002.

OWOLABI, J. et al. Causes and effect of delay on project construction delivery time. International Journal of Education and Research, v. 2, n. 4,p. 5-12, apr. 2014.

OYEGOKE, A. S.; AL KIYUMI, N. The causes, impacts and mitigations of delay in megaprojects in the Sultanate of Oman. Journal of Financial Management of Property and Construction, v. 22, n. 3, p. 286302, sep. 2017.

PEREIRA, E. S. S. Fatores associados ao atraso na entrega de edifícios residenciais. Florianópolis, 2012. 204 f. Dissertação (Mestrado em Engenharia Civil) - Programa de Pós-Graduação em Engenharia Civil, Centro Tecnológico, Universidade Federal de Santa Catarina, Florianópolis, 2012.

PEREZ, C. Proposta e implementação de um plano de qualidade para obras públicas de pequeno porte. Belo Horizonte, 2011. 181 f. Dissertação (Mestrado em Construção Civil) - Programa de PósGraduação em Construção Civil, Escola de Engenharia, Universidade Federal de Minas Gerais, Belo Horizonte, 2011.

POURROSTAM, T.; ISMAIL, Significant factors causing and effects of delay in Iranian construction projects. Australian Journal of Basic and Applied Sciences, Australian, v. 5, n. 7, p 450-456, 2011. 
PRASITNOK, K. et al. The professionals' perspective on the causes of project delay in construction industry. Journal of Physical Chemistry B, Washington, v. 8, n. 1, p. 28-48, 2017.

RASMUSSEM, A. F. M. Gestão de obras públicas: um diagnóstico sobre aditivos de contratos. São Paulo, 2013. 108 f. Dissertação (Mestrado em Arquitetura e Urbanismo) - Instituto de Arquitetura e Urbanismo, Universidade de São Paulo, São Paulo, 2013.

RIBEIRO, H. R. O. Análise das causas e do impacto financeiro de contratações adicionais em obras públicas. Goiânia, 2015. 209 f. Dissertação (Mestrado em Geotecnia, Estruturas e Construção Civil) Programa de Pós-Graduação em Geotecnia, Estruturas e Construção Civil, Escola de Engenharia Civil, Universidade Federal de Goiás, Goiânia, 2015.

RICARDINO, R.; SILVA, S.; ALENCAR, C. Causas frequentes de reivindicações contratuais. Revista Engenharia, São Paulo, v. 615, p. 90-94, 2013.

SAMBASIVAN, MURALI; SOON, YAU WEN. Causes and effects of delays in Malaysian construction industry. International Journal of Project Management, v. 25, n. 5, p. 517-526, 2007.

SAMBASIVAN, M. et al. Analysis of delays in Tanzanian construction industry transaction cost economics (TCE) and structural equation modeling (SEM) approach. Engineering, Construction and Architectural Management, v. 24, n. 2, p. 308-325, mar. 2017.

SANTOS, H. P. Diagnóstico e análise das causas de aditivos contratuais de prazo e valor em obras de edificações em uma instituição pública. Belo Horizonte, 2015. 172 f. Dissertação (Mestrado em Construção Civil) - Escola de Engenharia, Universidade Federal de Minas Gerais, Belo Horizonte, 2015.

SANTOS, H. P.; STARLING, C. M. D.; ANDERY, P. R. P. Estudo introdutório sobre aditivos contratuais em obras públicas de edificações de âmbito municipal. Revista Construindo, Belo Horizonte, v. 6, n. 2, p. 26-34, jul./dez. 2014.

SENOUCI, A.; ISMAIL, A.; ELDIN, N. Time delay and cost overrun in Qatari public construction projects. Procedia Engineering, v. 164, p. 368-375, 2016.

SHEHU, Z. et al. Cost overrun in the Malaysian construction industry projects: a deeper insight. International Journal of Project Management, v. 32, n. 8, p. 1471-1480, nov. 2014.

SILVA, R. V. S. Obras públicas: um estudo de caso em duas instituições federais de ensino de Goiás e Tocantins. Goiânia, 2014. 113 f. Dissertação (Mestrado em Engenharia) - Programa de Pós-Graduação em Engenharia de Produção e Sistemas, Pontifícia Universidade Católica de Goiás, Goiânia, 2014.

SIMÕES, C. R. M.; PEREIRA, R. R. Transparência na aplicação de recursos em obras públicas. Caderno de Finanças Públicas, Brasília, n. 12, p. 283-309, 2012.

SWEIS, G. et al. Delays in construction projects: the case of Jordan. International Journal of Project Management, v. 26, n. 6, p. 665-674, aug. 2008.

TIPILI, L. G.; YAKUBU, I. Identification and assessment of key risk factors affecting public construction in Nigeria: stakeholders perspectives. International Journal of Engineering and Advanced Technology Studies, Gillingham, v. 4, n. 2, p. 20-32, 2017.

YANG, J.-B.; OU, S.-F. Using structural equation modeling to analyze relationships among key causes of delay in construction. Canadian Journal of Civil Engineering, v. 4, n. 35, p. 153-164, 2008. 


\section{Felipe Campos Alvarenga}

Programa de Pós-Graduação em Engenharia Civil | Universidade Federal do Pará | Rua Augusto Corrêa, 1, Guamá | Belém - PA - Brasil | CEP 66075-110 | Tel.: (91) 3201-7390 | E-mail: felipealvarenga.eng@hotmail.com

\section{Luiz Maurício Furtado Maués}

Faculdade de Engenharia Civil, Programa de Pós-Graduação em Engenharia Civil | Universidade Federal do Pará | Tel.: (91) 3201-7254 | E-mail: maues@ufpa.br

\section{Paulo Cerqueira dos Santos Júnior}

Núcleo de Sistemas Ciber Físicos | Universidade Federal Rural da Amazônia | Av. Presidente Tancredo Neves, 2501, Terra Firme | Belém PA - Brasil | CEP 66077-830 | Tel.: (91) 3201-8284 | E-mail: pauloest16@gmail.com

Alcebíades Negrão Macedo

Programa de Pós-Graduação em Engenharia Civil | Universidade Federal do Pará | Tel.: (91) 3201-7254 | E-mail: anmacedo@ufpa.br

\section{Ambiente Construído}

Revista da Associação Nacional de Tecnologia do Ambiente Construído

Av. Osvaldo Aranha, $99-3^{\circ}$ andar, Centro

Porto Alegre - RS - Brasil

CEP $90035-190$

Telefone: +55 (51) 3308-4084

Fax: +55 (51) 3308-4054

www.seer.ufrgs.br/ambienteconstruido

E-mail: ambienteconstruido@ufrgs.br 